\title{
DIPTICO SOBRE EL TEATRO MEXICANO DE LOS TREINTA: BUSTILLO Y MAGDALENO, USIGLI Y VILLAURRUTIA
}

POR

\author{
GUILLERMO SCHMIDHUBER \\ University of Cincinnati
}

Con la creación de El Gesticulador (1937), se concluye cl periodo formativo del teatro mexicano, para nacer prometedor a la modernidad. Pudicra cjemplificarse gráficamente la trascendencia de esta pieza, con una hipérbola gcométrica, que en una de sus curvas englobe todo el teatro previo, y que con la otra abra la posibilidad csperanzadora del teatro mexicano del futuro. Por cso es de suma importancia, cstudiar cl teatro que antecede dircetamente a csta picza, tanto en la misma producción usigliana como en la de sus contemporáncos. Ahora que ha pasado más de medio siglo, podemos descubrir las influencias que los diferentes movimientos teatrales de entonces tuvicron en el teatro mexicano posicrior, y así diferenciar las obras trascendentes de las que no pasaron de ser vanguardias fugaces. Los csfuerzos nacionalistas de la Comedia Mexicana, formada en 1929 con los restos del llamado Grupo de los Sicte, y el de los movimientos más xcnofílicos de Ulises (1928) y Orientación (1932) han sido ampliamente estudiados ${ }^{1}$. Sin cmbargo, la importancia del Teatro de Ahora y de las obras usiglianas anteriores a El Gesticulador no ha sido suficientemente apreciada por la crítica y, ciertamente, ha sido ignorada por cl público mexicano. Este estudio pretende invitar al intcrés crítico hacia estos dos momentos que, como se verá, orientaron las directrices estéticas del teatro mexicano posterior. Además, este díptico constituye una crónica doble de la amistad literaria de Bustillo Oro y de Mauricio Magdaleno, en los años en que colaboraron en el Teatro de Ahora, y de la relación amistosa de Rodolfo Usigli y Xavier Villaurrutia en los años anteriores a la crcación de El Gesticulador.

\footnotetext{
' Ver entre otros a Magaña-Esquivel, Imágenes del teatro; Dauster, Ilistoria del Teatro hispanoamericano; y Nomland, Teatro Mexicano.
} 


\section{BUSTILLO ORO, MAGDALENO Y EL TEATRO DE AHORA}

Frank Dauster ha señalado recientemente la importancia de Bustillo Oro, en un excelente artículo titulado: La generación đe 24, el dilema del realismo:

[Bustillo Oro] modificó drásticamente el realismo en un intento por hacer un icatro épico... Resulta curioso que el dramaturgo acaso más sincronizado con cl teatro nuevo, y de fijo con el teatro del futuro, fuera un autor lejos de los experimentalistas y casi olvidado ya ${ }^{2}$.

Todas las historias del teatro mexicano incluyen el Teatro de Ahora. Para Magaña Esquivel es un "tcatro esencialmente político ... una novedad ... Sin embargo, a su reducido grado artístico corresponde su transitoriedad"'. Por su parte, Nomland afirma que sirvió "para cristalizar y dar ímpctu y prestigio al teatro de espíritu revolucionario"4. Una primera apreciación de Dauster scñala su "orientación panfletaria ... un realismo didáctico-social exageradamente crudo"s. Usigli cscribió en cl mismo año de las labores escénicas del Teatro de Ahora:

Todavía no hay una revolución técnica en esie movimiento; pero es porque aún no hay un dominio total de los pies clásicos del teatro. Más adelante ¿por que no?

Juan Bustillo Oro (1905) había nacido en un ambiente familiar que lo predestinaba al teatro. Su padre era administrador del teatro Colón, en la ciudad de México. En sus agradables memorias recuerda:

La diversión casi única de mi familia, en la comodidad de la entrada gratuita, era la asistencia constante a ese lugar que yo tenía por maravilloso. Debo de haberlo traído en la sangre, porque desde la primera vez que vi levantarse el telón, se hicieron de mí los duendes que lo levantaron. Allí mismo y en el acto, empezó mi educación como autor y director ${ }^{7}$

\footnotetext{
${ }^{2}$ Dauster, Frank, "La generación de 1924: el dilema del realismo," LATR 18/2 (Spring 1985): 13-22. Para otra valoración crílica ver el concienzudo artículo de Cucucl, Madeleine, "Les recherches Theâtrales au Mexico (1923-1947)", Les cahiers du CRIAR, Rouen, No. 127-7, p. 7-58.

3agaña-Esquivel, p. 75 y 80 .

Nomland, p. 270.

${ }^{5}$ Dauster, p. 64.

' Usigli, México en el Tealro, p. 134.

${ }^{7}$ Bustillo, Vida cinematográfica, p. 13.
} 
Además del tiempo pasado en este "palacio de la fantasía," jugaba largos ratos a los títeres, como también lo hicicron en su infancia Usigli y Leñero. Desgraciadamente el teatro Colón fuc convertido en cine en 1924, pero los quince años de continua convivencia con el mundo del teatro sembraron en aquel niño el gusto por cl espectáculo, a pesar de que sus estudios posteriormente lo encaminarian a la abogacía y a la aventura política frustrada del vasconcelismo al final de la década de los vcinte. En csos avatares de la vida política universitaria, Bustillo conoció al también joven abogado Mauricio Magdaleno (1906): "Otro pájaro de la derrota y ave nocturna de las cuevas escénicas," en descripción de su amigo ${ }^{8}$. Juntos decidicron olvidarse de la política e iniciar una aventura teatral:

\begin{abstract}
Apartarnos radicalmente del teatro en uso e intentar uno de sentido social, antiburgués, revolucionario. Lo titulamos Teatro de Ahora. Un macstro anticonformista, don Narciso Bassols, nos apadrinó desde la secretaría de Educación, nos cedió el caduco teatro Hidalgo de las calles de Regina".
\end{abstract}

La primera y única temporada del Teatro de Ahora comenzó cl 12 de febrero de 1932. Sc presentaron cuatro obras: Emiliano Zapata y Pánuco 137 de Magdalcno; Tiburón, una urasposición de Volpone (Johnson), claborada por Bustillo siguiendo la escenificada en $1928 \mathrm{cn}$ el Theatre de l' Atclicr de Paris ${ }^{10} ; y$ Los que vuelven de Bustillo que se esurenó cl último día de la temporada (12 de marzo). Las crónicas tcatrales de la ćpoca califican de "pomposo" al título de Tcatro de Ahora y niegan el éxito a esta "nueva tentativa para crearle ambiente a los autores localcs, fracasando más que por nada por cl cspíritu de cgolatría que la engendró"1. Otro cronista comenta que "cs una real aportación que ha sido sentida y percibida por todos. Y que cl hecho que más patentemente lo demuestra es su discusión inicial, no importa que lucgo la tácita consigna del silencio haya hecho cl vacío final en su entorno"12. Bustillo recordaría en sus memorias algo similar:

Apenas tuvimos espectadores. Recientes los estragos y sufrimientos de nuestra revolución, la gente parecía resistirse a renovarlos en un espectáculo que forzosa-

\footnotetext{
${ }^{8}$ Bustillo, Vida cinematográfica, p. 82.

${ }^{9}$ Bustillo, Vida cinematográfica, p. 82.

${ }^{10}$ Dato proporcionado por Madelaine Cucuel, ver nota 2.

"Roberto El Diablo, "Nuestro año teatral," Revista de revistas 1933, Vol. 1-1, No 1118, p. 21.

${ }_{12}$ Mota, Fernando, "Nuevo ciclo del Teatro de Ahora," Revista de revistas 1932, Vol. 104, No. 1143 , p. 9-10.
} 
mente tenía que remover aquellas amarguras. Nos sentimos heridos directamente por nuestra patria, y pensamos en emigrar a parajes menos hostiles ${ }^{13}$.

Los dos amigos se embarcaron en Veracruz rumbo a España, el 10 de julio de $1932^{14}$, a pesar de que existía su promesa de una segunda temporada del Teatro de Ahora ${ }^{15}$, y de que irónicamente se habia estrenado el $1^{\circ} \mathrm{de}$ julio su adaptación a teatro de revista de El Periquillo Sarniento, en la que "los bisoños libretistas ... triunfaron ruidosamente," en apreciación del mismo cronista que los acusaba de ególatras ${ }^{16}$.

La estancia de los dos mexicanos en España se prolongó hasta abril de $1933^{17}$. Conocicron y conversaron con Unamuno, con Valle Inclán, con Lorca. Sc hicicron asiduos al café de La Granja el Henar, en donde intimaron con el novelista Ramón J. Sender. En el saloncito del teatro Español, fucron recibidos en múltiples veces por Margarita Xirgú y Enrique Borras, ahí conocicron a Alcjandro Casona y a Paulino Masip. Rivas Cherif, por entonces director del Tcatro Español, accptó montarles una obra a cada uno, pero complicaciones con la aceptación de la pucsta de El estupendo cornudo de Commclynck, lo impidicron. Sender les ayudó a publicar, de nuevo paralelamente, dos volúmenes de teatro en la editorial revolucionaria Cenit, de Magdaleno incluycron Pánuco 137, Emiliano Zapata y Trópico, y de Bustillo, Los que vuelven, Masas y Justicia, S.A.; ambos libros llcvan dedicatorias a Bassols y a Sender. Su regreso a México marcó un cambio de derroteros lejanos al teatro, Magdaleno escribiendo narrativa y guionismo, y Bustillo dedicándose a la dirección cinematográfica; acaso porque México "no ofrecicra alguna oportunidad de verter al drama su conciencia social y sus angustias," en palabras escritas por Magdaleno con motivo del estreno de una de sus obras en Bucnos Aires, cn 1937'.

Una mirada de escrutinio crítico sobre las obras de Bustillo Oro descubre una sorpresa. La más conocida hoy de sus piczas es San Miguel de las Espinas, sobre el problema agrario y la reivindicación de la ticrra, su autor la llama trilogía dramática de un pedazo de tierra mexicana; sus cuarenta personajes nominales, además de grupos de rurales, campesinos y soldados, y de dos coros de mujeres y

\footnotetext{
${ }^{13}$ Bustillo, Vida cinematográfica, p. 82.

${ }^{14}$ Bustillo, Vida cinematográfica, p. 83.

${ }^{15}$ Se prometían cuatro obras: Exito, Vivir, Justicia, SA., y Masas, ver artículo citado en la nota 12.

${ }^{16}$ Roberto El Diablo, mismo artículo citado en la nota 11.

17 Los datos de la estancia española los saco de Bustillo, Vida cinematográfica, p. 83-86.

${ }^{18}$ Magaña-Esquivel, p. 78.
} 
de hombres, no llegan a constituirse en protagonistas, cediendo el lugar a la tierra mexicana. La pieza es vigorosa, bien dialogada y muy cercana al arte pictórico revolucionario y a las imágenes cinematográficas sobre la revolución mexicana de las décadas siguientes. Es la única de sus piezas que ha alcanzado tres ediciones y cl estreno. Los que vuelven bien pudiera ser la primera obra teatral de temática chicana escrita en la historia, la perfección de su estructura dramática es notoria y cl grado de humanización de sus personajes es el más logrado de su teatro. La trama narra la desmembración de una paupérrima familia mexicana que había emigrado a los Estados Unidos para huir de la revolución y el hambre, pero que es deportada con violencia por la crisis nortcamericana de 1927, quedando en una ciudad industrial una hija casada con un obrcro nortcamericano, quicn es cl delator de la deportación; $y$ un hijo mutilado por un accidente fabril; mientras los padres acaban muriendo antes de icrminar el penoso viaje de retorno. La pieza posee un crudo realismo, remarcado con tintes de aguafucrte, que gencra un verismo escénico desconocido en el teatro mexicano anterior. El lenguaje de Los que vuelven logra una gran efectividad dramática, con la utilización de expresiones populares con visos líricos:

Chema - No niegues a tu tierra la humedad de tu sangre, los huesos de tus hijos, el sudor de tu frente ${ }^{19}$.

A pesar de que la picza posec algunos elementos melodramáticos que perjudican su contenido testimonial, la inclusión del detallismo en la acción - se fuma marihuana_ la peculiaridad de los personajes - la falta de la mano derecha cn un personaje-, hace que la pieza se acerque más al teatro documental.

La obra macstra de Bustillo Oro es, a mi parecer, Masas. Obra que nunca ha sido cstrenada, no obstante ser pionera en la literatura latinoamericana en utilizar al dictador como personaje; adelantándose a En la luna (Huidobro, 1934) y a Saverio el crucl (Arlt, 1936), en el tcatro, y en la novela a El scñor Presidente de Asturias por más de una década. La picza presenta la vida política de un país latinoamcricano durante la caída de unạ dictadura a causa de una revolución, y la instauración de otra dictadura. Los personajes están excelentemente humanizados: Porfirio Neri pasa de ser un idealista revolucionario a ser el político saborcador del poder; Máximo Forcada, es el cterno idealista social que personifica la conciencia de la lucha popular; y Luisa Neri, hermana del claudicante revolucionario y esposa del mártir, es un personaje feminista inusitado en el teatro latinoamericano de esta década. Masas hace derroche de nuevas técnicas teatrales: utilización de la radio

${ }^{19}$ Bustillo, Los que vuelven p. 70 . 
y el cinematógrafo, altoparlantes, grabaciones, entradas de actores por el foro, y muchas aplicaciones más del tcatro de Piscator, cuyas ideas cran aún mundialmente consideradas como vanguardia; coincidentemente la misma editorial Cenit de Madrid acababa de publicar (1930) el Teatro Político de este visionario del lcatro ${ }^{20}$. Sin cmbargo, cl aspecto más logrado de la dramática bustillana es la capacidad volitiva de los personajes, de herencia ibseniana, cuya calidad de rcalización no tuvo paralclo hasta El Gesticulador.

$J$ usticia, S.A. es una obra sobre la responsabilidad y la integridad de un juez. Sicndo Bustillo abogado, logra dar a esta pieza cierta efectividad. Entre los casos jurídicos mencionados sobresale cl del aborto, por su novedad sobre el escenario. En la mejor escena, cl Jucz sc ve a sí mismo, mediante un subterfugio dramático surrealista, en cl acto de cometer el mismo delito que juzga en otro, y se obscrva laborar como obrero en una capitalista Compañía de Justicia Incorporada, manejando una máquina que acuña monedas de oro y que es lubricada con sangre y carnc humanas. Esta impresionante escena utiliza muñecos y proyecciones, y tiene cicrtas concordancias con Trescientos millones (1932) de Arlt en la forma de llevar el conflicto a lo onírico; además la utilización de la máquina traga-hombres, verdadero fetichismo dramático que corporiza el conflicto en un objeto, que recuerda al altar de Baal de La fiesta del hierro (1940), tambićn de Arlt.

El teatro de Mauricio Magdaleno' abusa de la explicitez de temas y del melodramatismo patente cn casi todas sus subtramas; además sus obras carecen de verdadcra experimentación en la búsqueda de nuevas formas de llevar el conflicto dramático a la escena. Los abusos de una compañía chiclera nortcamcricana en territorio chiapaneco son presentados en Trópico, pieza terminada en Madrid en 1932, y que adolcce al igual que Pánuco 137, obra sobre la explotación extranjera del petrólco mexicano, de convertir el espacio dramático en el verdadero protagonista del drama, inversión bienvenida en la novela, pero que desdibuja del conflicto dramático, ya que este nunca puede ser entre la naturaleza y el hombre. Su mejor picza cs Emiliano Zapata por ser pionera de un nucvo tcatro histórico más cercano al realismo, en cl que los personajes son simplementc hombres y no hérocs, enfoque realista que haría escucla posteriormente, con cl Moctezuma II de Magaña y El martirio de Morelos de Leñcro.

A su regreso de España, Bustillo inició su carrera de guionista con una adaptación cincmatográfica del mismo Tiburón volponiano y, en seguida, de $E l$

${ }^{20}$ Citado por Nomland, p. 270 .

${ }^{2 i}$ Para otra evaluación del teatro de Magdaleno ver Nomland, p. 272-74; y la tesis de Parle, Dennis J. El tiempo y la historicidad como factores estructurales en la obra de MM, p. 229 34. 
compadre Mendoza, utilizando un cuento de Magdaleno escrito en España; micntras que su amigo laboraba en un pucsto burocrático y se iniciaba como novelista. Nuevamente el tcatro los persiguió con una última ironía, el grupo recientemente fundado de Los Trabajadores del Teatro llevó a la escena en 1933 Trópico y San Miguel de las Espinas; esta última picza fue oficialmente retirada de escena al encontrarle paralclismos con un asesinato reciente en la vida política mexicana. Ni Magdaleno ni Bustillo volvieron a intcresarse en la dramaturgia ${ }^{22}$, en bucna parte porque lograron triunfar en sus nuevas profesiones, Magdaleno se convirtió en uno de los narradores más sobresalienies en el periodo anterior a Agustín Yáñcz, especialmente con su novela indigenista El resplandor (1937); como guionista logró un ailto nivel de excelencia, colaboró con el "Indio" Fernández y con Buñucl. Bustillo llegó a dirigir cincuenta y ocho películas, algunas de gran estima entre los cinćfilos como Ahí está el detalle que consagró a Cantinflas; sobresalen sus adaptaciones cinematográficas a múltiples obras de la litcratura universal: Marivaux, Pedro Antonio de Alarcón, Sardou, Galdós, Rómulo Gallegos, Arniches, Rubén Romcro, Mook, y otros.

En cl mismo mes y año del Teatro de Ahora, Usigli cicrra su magistral ensayo crítico México en el Teatro con estas palabras:

Finalmente, el momento teatral de México no tardará mucho. Pertenece a la próxima generación sin duda. No es posible poner mayor trabajo ni mayor dolor en la herencia que para ella se está preparando, y su expresión, caudalosa y rica, habrá de ser la expresión de este trabajo y de este dolor ${ }^{23}$.

Usigli no esperó a que la siguiente generación fundara cl tcatro mexicano, ćl mismo pasó de ser profela del advenimicnto a ser su creador con El Gesticulador, picza que a mi ver tienc muchas concordancias temáticas y dramáticas con $\mathrm{cl}$ Tcatro de Ahora: la geografía nortcña - Pánuco 137-, la humanización del conflicto temático cn una familia - Los que vuelven-, la herencia revolucionaria y la conciencia individual - Masas_, la mezcla de la historia y la ficción —la

2 Magdaleno escribió además El Santo Samán, estrenada en 1935, y Ramiro Sandoval (1936), inćditas. Bustillo había escrito en 1931 La honradez es un estorbo, y en 1933 Un perito en viudas, ninguna comedia llegó a estrenarse ni se ha publicado. Posteriormente estrenó Una lección para maridos (1936); y en 1953 escribió Mi hijo el mexicano, publicada en 1966 y sin estreno. Para el tcatro frívolo, ambos escribicron dos revistas más, El corrido de la revolución y El pájaro carpintero, por desgracia hoy perdidas. Además Bustillo había colaborado en la revista frívola Kaleidoscopio (1920).

${ }^{23}$ Usigli, México en el Teatro, p. 157. 
nacionalización de la riqueza en Masas -, y la esperanza usigliana hacia un mejor futuro social que es palpable en todas las obras del Teatro de Ahora. De forma similar podemos encontrar interesantes concordancias de las Comedias Impolíticas de Usigli (1933-35) y de su farsa impolítica La última puerta, con los idcales estéticos y temáticos del Teatro de Ahora. Además, cl reciente teatro documental de Leñero, con sus tintes de realismo realista y algunas piezas de la gencración llamada Nueva Dramaturgia Mexicana - El extensionista de Santander, Las razones de Elvira de Rascón, y Por las tierras de Colón de Schmidhuber - han continuado la tradición testimonial iniciada por cl Teatro de Ahora.

\section{USIGLI Y VILLAURRUTIA ANTE LA ULTIMA PUERTA}

Entre las treinta y nueve obras conocidas de Rodolfo Usigli existe una picza casi olvidada, que nunca ha llegado a la escena y que se publicó veintisicte años despućs de que se cscribicra: La última puerta, Farsa impolítica para ser dividida en dos escenas y un ballet intermedio ${ }^{24}$. Al ser publicada, Usigli dedicó csta obra a su amigo Xavier Villaurrutia, con una larga carta:

Querido Xavier: Debo a nuestras conversaciones que usted ha hecho camino siempre por el filo de la inteligencia y bajo la esfera de la lucidez, mi interés por la farsa que me parece una modalidad más depurada y poética del teatro ...25.

Usigli y Villaurrutia habían compartido una estancia de dicz meses en los Estados Unidos, gracias a una beca Rockefeller para cstudiar teatro en la Universidad de Yale. La obra había sido comenzada antes de la partida, en 1934, y fuc terminada durante su estancia en New Haven, Usigli mismo recordaría este hecho cn un escrito fechado en 1961, cn Bcirut:

La terminé en New Haven en 1936, por disciplina y también porque la relectura del primer cuadro me devolvió a la agridulce atmósfera de las antesalas mostrándome que el problema y la pequeña farsa seguían vivos ${ }^{26}$.

\footnotetext{
${ }^{24}$ Usigli, Teatro Completo I, p. 404-41.

${ }^{25}$ Usigli, Teatro Completo, p. 404. La última puerta también está dedicada "al único ministro que en México recibe a los pretendientes," sin nombrar la persona. La dedicatoria era para Eduardo Vasconcelos, hermano de José Valsconcelos, según consta en Usigli, Teatro Completo III, p. 432.

${ }^{26}$ Usigli, Teatro Completo III, p. 432. Convendría hacer un análisis más completo de los paralelismos de las Comedias Impolíticas de Usigli con el Teatro de Ahora.
} 
Como crónica de la estancia en New Haven, existen publicadas las diecisćis Cartas de Villaurrutia a $\mathrm{Nov}^{27}$, dos de ellas con una postdata de Usigli. La primera carta fechada es de octubre de 1935, y la última es de julio de 1936. Por cllas conocemos los estudios y cl diario vivir de estos escritores en ciernes. Largo es el repertorio de piczas que ambos tuvieron la sucrie de ver en la escena americana, sobresalen: An American Tragedy de Dreiser —en una versión de Piscator-. Santa Juana de Shaw, Murder in the Cathedral de Eliot y Espectros de Ibsencon la actuación de la Nazimova-.

Tanto Villaurrutia como Usigli no eran desconocedores de las vanguardias del tcatro curopeo y nortcamericano. Villaurrutia había colaborado con el teatro Ulises (1928) y con cl teatro Orientación; sus dos únicas piczas hasta la fecha escritas Parece mentiray ¿En qué piensas? habían sido representadas en la tercera (1933) y la cuarta temporadas (1934) de este último movimiento de vanguardia del tcatro mexicano. Por su parte, Usigli tenía una producción dramática más abundante, había escrito El apóstol en 1931, Falso drama y 4 Chemins 4 en 1932; y sus tres comcdias impoliticas: Noche de estio (1933-1935), El presidente y el ideal y Estado de sitio, estás últimas antes de partir a los Estados Unidos en 1935. De cstas obras sólo El apóstol había alcanzado una lectura escenificada en $1931^{28}$. Ninguna de las obras teatrales de estos autores había sido aún publicada.

Si analizamos las obras que escribicron estos escritores viajeros a su retorno de la estancia en Yalc, encontraremos valiosos logros. Usigli fecha en $1936 \mathrm{su}$ Alceste -transposición mexicana de Le Misanthrope - y El niño y la niebla; y al año siguiente Medio tono y El Gesticulador. Por su lado, Villaurrutia cscribe II a llegado el momento y Sea usted breve, en cl primer auto aparece por vez primera cl tema de la muerte, y en la segunda picza anticipa el teatro social con cl tema del control de la natalidad. Aunque Invitación a la muerte lleva la fecha de 1940, debe haber sido escrita con anterioridad, ya que es mencionada en una carta a Novo el $17 \mathrm{de}$ encro de 1936 $6^{29}$; además esta obra guarda paralclismos innegables con su famoso pocmario Nostalgia de la Muerte (1938), específicamente con el pocma Nocturno en que habla la muerte, fechado en 1935, en New Haven ${ }^{30}$.

\footnotetext{
${ }^{27}$ Villaumulia, Xavier. Cartas de Villaurrutia a Novo [1935-1936]. México: Ediciones de Bellas Artes, 1966.

${ }^{28}$ Usigli, Teatro Completo III, p. 280.

${ }^{29}$ Villaurrutia menciona en la carta dos obras con temática de la muerte: Dead End y Till the Day / Day, y agrega: "Por mi parte yo veo la oportunidad de que alguien haga representar con conocimicnto de causa, mi Invitación a la muerte."

${ }^{30}$ Villaurrutia, Obras, p. 54.
} 
La última puerla es una farsa de tema político que critica la excesiva burocracia mexicana. Su trama es sencilla ${ }^{31}$ : En la antesala de un Ministro, un grupo de personas espera una audiencia. La primera escena recorre un día de espera, desde la primera hora con la llegada del mozo que abre los balcones, hasta la despedida por la noche, sin que nadic haya logrado ser recibido para presentarle al Ministro los ruegos y deseos de que han hablado durante el día los peticionarios - estudiantes, artistas, un periodista, un diputado y ciudadanos comunes-. Los burócratas están representados por el secretario particular, dos ineficientes secreLarias y cl mozo. La escenografía ha presentado la aniesala de un ministcrio vista desde afucra, scgún informa la primera acotación:

Al levantarse el telón, aparece otro con una larga fila de balcones iguales, cerrados, cuyos batientes y persianas empiezan a ser abiertos, desde dentro, por un mozo uniformado .... Queda a la vista una habitación espaciosa, bien al fombrada, Ilena de candelabros, arañas y cómodos sofás y poltronas de diversos lipos ... dos o tres escritorios modernos, una máquina de escribir, y al fondo ... una única puerta de color caoba muy brillante ${ }^{32}$.

Una común antesala gubernamental latinoamericana. Cac el telón y tienc lugar el Ballet Intermedio de la Espera que termina con la formación de un monumento simbólico con los cuerpos de los bailarines. La segunda escena sucede "cuando ha transcurrido una cntidad de tiempo absolutamente indefinible." Además del deterioro del mobiliario debido al ticmpo, los personajes, que son los mismos de la primcra escena, ahora son más vicjos. El ministro nunca ha sido visto, y se rumorca que no existc. Uno de los esperadores -El Desconocido-incita al grupo a la rebelión y todos lo siguen con la paciencia agotada:

Tiran todas las puertas, menos la última; rompen las estatuas ... reservando para el momento final la puerta resplandeciente, que continúa cerrada ... Se dirigen tumultuosamente hacia ella, cuando, por sobre todos los ruidos, se oye un maravilloso clic, y la última puerta se entreabre ... ${ }^{33}$.

Y secscucha la voz del Ministro: "¿Dónde diablos cstá mi boquilla de ámbar?” Los amotinados retroceden consternados y abandonan la sala, "sólo los dos vicjos permanccen entre los escombros de la antesala" ${ }^{\text {". }}$. Buena parte de la cscenografía

${ }^{31}$ Esta redacción de la trama de La última puerta completa la incluía en Mendoza López, Margarita. Teatromexicano del sigloXX. México: Instituto del Seguro Social 1987, p. 308.

${ }^{32}$ Usigli, Teatro Completo I, p. 405.

${ }^{33}$ Usigli, Teatro Completo I, p. 439-40.

${ }^{34}$ Usigli, Teatro Completo I, p. 441. 
ha sido destruida por la ira de los personajes, recibiendo así cl espacio tcatral la resultante de las fucrzas que han constituido la dinámica del conflicto, y que al no tencr una solución dentro del mundo sicológico de los personajes, éstos proyectan su frustración de la espera contra el cspacio de su espera. Entre los mecanismos de defensa identificados por Freud para escapar de la frustración, está la agresión, que consistc en hacer uso de la violencia para destruir cl obstáculo que impide la realización del desco. La utilización del espacio no sólo como receptáculo de la acción teatral, sino también como elemento protagónico, es una característica de los teatros de vanguardia. Por primera vezen la historia del teatro mexicano, Usigli experimenta en este sentido.

Los personajes de La última puerta son cuando menos treinta. Todos están tipificados al cstar su sicología sujeta a una funcionalidad: El Periodista, El joven Empicado que no trabaja, El Estudiante, El Vagabundo, El Diputado, El Espía, El Escritor, El Pocta, El Inventor - de un robot que puede sustituir al ministro-, clc. O tipificados a una sola característica esencial: Una pareja — novios primero y después casados-, La Scñora vicja, El Hombre gordo, elc. Algunos personajes poscen mayor humanización, como El Secretario particular, El Mozo, y las dos sccretarias: La señorita Bcrtha y La señorita Lola -quien intenta infructuosamente seducir al evanescente Ministro, presentándose desnuda a tomar dictadoDestacan dos personajes cnigmáticos: El Desconocido - protagonista_, del que se sirve Usigli como raisonneur, y el clusivo antagonista, El señor Ministro, de quien se escucha la voz pero nunca es visto por nadic ... ni por el público. En la segunda escena toma por primera vez la palabra El Desconocido, la acotación correspondiente cs muy interesante:

De pronto, El Desconocido salta de su asiento y, situándose a media escena, GESTICULA, congestionado, hasta que rompe los diques y se arroja tumultosamente sobre todos [Las mayúsculas son mías.]:

El Desconocido - ¿Para esto hicimos la revolución? ¿La revolución de ayer, de hoy, de mañana, de siempre? ${ }^{35}$.

Más adelante, El Desconocido agrega, en varios parlamentos:

El Desconocido - En primer lugar, están aquí, así, porque son unos cobardes, unos seres a medias, invertebrados, cadáveres de la burocracia, artistas de ministerio, escritores de periódicos no leídos, holgazanes ...

Todos vinieron aquí a pedir algo, porque no nos atrevemos a hacer nada sin el gobierno ...

${ }^{35}$ Usigli, Teatro Completo I p. 435. 
Pero yo también hice mi primera antesala por un ideal; luego maduré, y seguí haciéndo laspor una idea; ahora no vine sino a buscar pan. Mi idea desapareció, mis ideas se dispersaron ... no es posible encerrar los ideales y las ideas en una sala de espera ....

Indudablemente EI Desconocido pertenece a csos personajes que Usigli creó en "el linaje de la verdad". En 1960, Usigli señaló que hay fragmentos de Alcestes que poseen "paradógica tangencia" con El Gesticulador, e igualmente con el Osvaldo Rey, el protagonista de La exposición —retrato dramático del pintor mexicano Manucl Rodríguez Lozano--. El Desconocido bien pudiera ser el primer apunte usigliano de César Rubio de El Gesticulador.

En la dedicatoria de La última puerta, Usigli recuerda sus conversaciones con Villaurrutia sobre la Farsa, y agrega:

No pretenderé que sea usted precisa y absolutamente el culpable de qué incurra yo en ese género, pero su presencia mental en mí vino a anudar oportunamente varias ideas dispersas ... ${ }^{37}$.

La Farsa, aunque tan antigua como Aristófanes y Plauto, ha alcanzado cnorme desarrollo en el tcatro contemporánco - Ioncsco, Beckett, Jorge Díaz-. En clla "los sentimientos son clementales, la intriga construida tontas y a locas: la alegría y cl movimiento lo cnvuelven todo"sz. "Esta rapidez y esta fucrza otorgan a la farsa un critcrio subversivo ... el espectador se venga de las limitaciones de la realidad y de la sabia razón"’’s. La última puerta es el primer experimento fársico en cl teatro mexicano contemporánco, teniendo como antecedentes las Comedias Impolíticas usiglianas, y adclantándosc, en cuanto farsa, a Sea usted breve de Villaurrutia.

La cstructura de la obra cs inusitada: un acto con un ballet intermedio, en el que hay un recitativo con un largo pocma titulado Ballet Intermedio de la Espera:

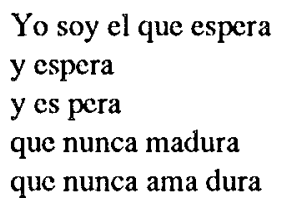

${ }^{36}$ Usigli, Teatro Completo III, p. 436-37.

${ }^{37}$ Usigli, Teatro Completo I, p. 404.

${ }^{38}$ Mauron, C. Psychocritique du genre comique. Paris: Corti 1964, p. 36. Citado por Pavis, Patrice. Diccionario del Teatro. Barcelona: Paidos 1980, p. 218.

${ }^{39}$ Pavis, Patrice. Diccionario del Teatro. Barcelona: Paidos 1980, p. 404. 


\author{
labor de ocioso \\ ¿Labore el ocioso? \\ Lo ocioso es pedirlo, \\ pedir lo imposible, \\ pedirlo imposible $e^{40}$.
}

Pocma que indudablemente parodia el estilo poćtico villaurtiano de los pocmas escritos durante la temporada compartida en New Haven, como por cjemplo este fragmento del Nocturno en que nada se oye:

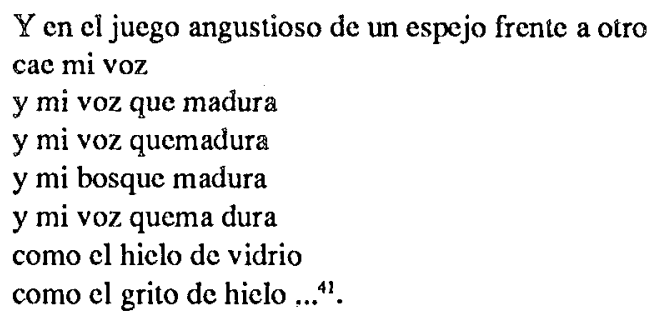

Además hay en La última puerta, alusiones a las obras de Villaurrutia y a su persona, algunas a nivel de chiste privado, como por ejemplo:

El Periodista. ¡Ah, ya! ¿Tiene el Sr. Ministro una amiga?

El Mozo. ¿Qué?

El Periodista. Sí, hombre, una amiguita, una ...

El Mozo. ¡A h, ya entiendo! No lo sé, mejor dicho, no sé cual de ellas es su amiga, o si son las tres ${ }^{42}$.

Alusión incuestionable a la ambigüedad de las tres scñoras en Parece mentira de Villaurrutia. El Ballet pide que los bailarines aparezcan con abrigos y sc los quiten para quedar en pijamas, ¿scrá este un recuerdo de los meses de convivencia familiar en el apartamento de 1231 Chapel St., en New Haven? El personaje de El Pocta no tiene parlamento, sin embargo El Desconocido lo alude al decir: "El pocta mismo necesita ser burócrata, y no sabcmos cómo nace a las lctras: si con un libro de versos o con un empleo" 4 , alusión a los puestos oficiales que Villaurrutia tuvo.

to Usigli, Teatro Completo I, p. 425.

41 Villaurrutia, Obras, p. 47.

${ }^{42}$ Usigli, Teatro Completo I, p. 407.

${ }^{43}$ Usigli, Teatro Completo I, p. 437. 
El tema del salario del pocta está presente también en un poema de Usigli, cscrito el 20 de encro de 1936, en New Haven:

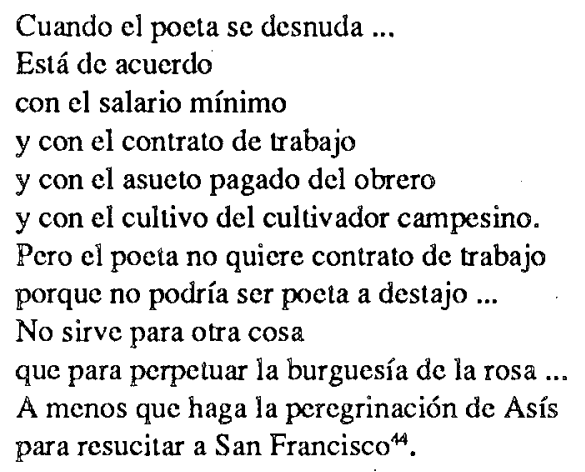

Pocma alusivo al Nocturno Rosa ("Yo también hablo de la rosa ...") de Villaurrutia y a su visita a San Francisco, mientras Usigli permanecía en Pasadena, California, cuando ambos se refugiaron del invierno $1936 \mathrm{cn}$ las cálidas costas californianas.

La última puerta es realmente el primer umbral por el que pasó el teatro mexicano para alcanzar la contemporancidad. Es una pieza de transición que apunta, un año antes, hacia $E l$ Gesticulador. Además csta obra prcludia cl teatro del Absurdo que estaba por nacer, como lo ha señalado José Emilio Pacheco:

Prefigura el teatro del absurdo mediante una estilización nada exagerada de lo que ocurre en esos sitios en donde se practica la tortura por la espera y la esperanza ${ }^{15}$.

La espera a lo Godot en un ministerio, se conviente en el fin de la existencia, y los ciudadanos llegan a preferir cl no ser recibidos. Usigli mismo reconoció esta semejanza en un postscriptum fechado en 1963, agregado en su prólogo titulado "Antesala para La última puerta":

Al releer La úllima puerta ... me ha parecido sentir un olorcillo particular que se respira actualmente en muchos teatros del mundo: el del absurdo de los actuales

44 Usigli, Tiempo y Memoria, p. 74-75.

As Pacheco, José Emilio. "Prólogo" a Usigli, Tiempo y Memoria, p. 12. Este ensayo es uno de los mejores que se han escrito sobre Usigli, no sólo como dramaturgo, sino también como pocta y novelista. 
neoexpresionistas y seudoneosurrealistas, sillas, balcones, cantantes calvas y, sobre todo, el de los que esperan a Godot en esa antesala. Quizá me equivoco ${ }^{46}$.

El tema de la espera está vinculado con el de la muerte, tanto en esta obra como en los pocmas que Usigli compuso en New Haven: Agonia, Este carnaval en silencio, Introducción trunca, Ojos del tiempo ...:

\author{
Vivir es morir. \\ Pero no ser ni estar siendo \\ pero esta hora es la que nada vive \\ cn la que nada muere \\ porque todo agoniza solamente ... ${ }^{47}$.
}

Además en el Recitativo del Ballet de la Espera hay dos menciones de la muerte. También en los pocmas de Villaurrutia pertenecientes a esta temporada, hay una presencia continua de la mucrte. No ha de extrañar el tema de la mucrte en La última puerta, ya que los elementos del tcatro del Absurdo que posec le dan la posibilidad de recrear un nivel ontológico, con personajes que luchan infructuosamente por resolver sus problemas temporales por la intervención ministerial de un quasidios, scr en cl que depositan su esperanza aun cuando dudan de su cxistencia, en un mundo cn donde la última puerta llega a ser el umbral entre la vida y la mucrte. Desde csta perspectiva ontológica, la inclusión del Ballet de la Espera adquicre mayor sentido y unidad estilística con el resto de la obra.

Muchas de las csperanzas que Usigli le exigió a la vida aún quedan incumplidas. Su desco primordial de fundar el teatro mexicano ha sido ampliamente alcanzado a partir de El Gesticulador; pero su influencia en las generaciones actuales y futuras de dramaturgos latinoamericanos está aún por venir. Además, la puesta cn cscena a lo largo del mundo hispánico de La última puerta y de otras obras - El gran circo del mundo, ${ }_{\text {iB }}$ uenos días, señor Presidente!, y Los Viejos ${ }^{48}$ todavía espera con impaciencia cn la antesala del Teatro Latinoamericano. $L a$ última puerta no es sólo una de las más duraderas obras de Usigli, sino también

\footnotetext{
${ }^{16}$ Usigli, Teatro Completo III, p. 433. En este prólogo, Usigli enumera las distintas antesalas donde ha esperado, comenzando con el recuerdo de la antesala a la que su madre lo llevó cn su primera edad, para pedirle una beca a don Porfirio Díaz, presidente de México, pero en esa ocasion si fue recibido y la petición fue otorgada.

${ }^{47}$ Usigli, Tiempo y Memoria, p. 63.

${ }^{48}$ Los Viejos es una de las obras más interesantes de Usigli, también en ella utiliza clementos prestados del Ballet una musa bailarina - La Muchacha-cierra el triángulo formado por El Vicjo Dramaturgo y El Joven Dramaturgo. Esta obra bien pudiera ser cl testamento
} 
una que con mayor excelencia lleva a la escena el tema de la espera y la esperanza, que llegaria a ser leitmotiv de la dramaturgia usigliana. Por eso el Ballet de la Espera bien pudicra ser una plegaria del autor:

Yo soy el que espera
y el que desespera.
Mejor que muera
para esperar más ...49.

Versos que necesariamente recuerdan el epitafio que Usigli pidió para sí mismo:

Aquí yace y espera

R.U.

ciudadano del Teatro.

\section{CONCLUSION DEL DIPTICO}

De los logros de los movimientos del periodo formativo de la dramaturgia mexicana-Comedia Mexicana, Ulises y Orientación-, nada ha vuclto a ser llevado a escena y poco ha influido en las nuevas tendencias dramatúrgicas. Horroriza lecr la enorme nómina de autores mexicanos pertenecientes a este periodo formativo que ha sido absorbido - como los mucrios a la naturaleza-a la muda tradición teatral, sin que sus nombres ni sus piezas digan nada a los tcatristas mexicanos de hoy. Pocos dramaturgos parecen seguir vigentes - Usigli y Villaurrutia-, otros ya se encaminan al olvido - Gorostiza, Novo y Lazo-, otros ya han sido injustamente olvidados —el Grupo de los Siete y La Comedia Mexicana-, y por último hay otros que están en proceso de retorno y recvaluación -Bustillo Oro y José Joaquín Gamboa-. Los cuatro siglos de tcatro en méxico han formado lo que, con cufcmismo, podríamos llamar el inconsciente colcctivo del teatro mexicano, csa sumatoria que permanece cuando todo parece haber sido olvidado. Sin embargo, visto el panorama desde nuestro distanciamiento temporal, podemos reconocer que han habido momentos que fucron decisivos para la

literario de su autor. Ver Labinger, Andrea, "Age, Alienation and the Artist in Usigli's Los viejos," LATR Spring 1981, pp. 41-47, y Schmidhuber, Guillermo, "Los Viejos y la dramaturgia mexicana," Les Cahiers du CRIAR, Université de Rouen 1987, No. 127-7, pp. 127-33.

${ }^{49}$ Usigli, Teatro Completo I, p. 426. 
orientación de las directrices que había de seguir el teatro mexicano. Indiscutiblemente, el Teatro de Ahora y, especialmente, el teatro usigliano de los años treinta, son dos momentos cruciales y, acaso, los más esperanzadores, del teatro mexicano moderno. 
